LLYMP9802064C MOL.19980423.0215

\title{
Long-Term Corrosion Testing of Candidate Materials for High-Level Radioactive Waste Containment
}

\author{
J.C. Estill \\ S. Doughty \\ G.E. Gdowski \\ S. Gordon \\ K. King \\ R.D. McCright \\ F. Wang
}

This paper was prepared for submittal to the

\section{International High-Level Radioactive Waste Management Conference}

Las Vegas, $N V$

May 11-14, 1998

\section{October 1997}

This is a preprint of a paper intended for publication in a journal or proceedings. Since changes may be made before publication, this preprint is made available with the understanding that it will not be cited or reproduced without the permission of the author. 
This document was prepared as an account of work sponsored by an agency of the United States Government. Neither the United States Government nor the University of California nor any of their employees, makes any warranty, express or implied, or assumes any legal liability or responsibility for the accuracy, completeness, or usefulness of any information, apparatus, product, or process disclosed, or represents that its use would not infringe privately owned rights. Reference herein to any specific commercial product, process, or service by trade name, trademark, manufacturer, or otherwise, does not necessarily constitute or imply its endorsement recommendation, or favoring by the United States Government or the University of California. The views and opinions of authors expressed herein do not necessarily state or reflect those of the United States Government or the University of California, and shall not be used for advertising or product endorsement purposes. 


\title{
Long-Term Corrosion Testing of Candidate Materials for High-Level Radioactive Waste Containment
}

\author{
John C. Estill \\ Scott Doughty \\ Gregory E. Gdowski \\ Steven Gordon \\ Kenneth King \\ R. Daniel McCright \\ Francis Wang \\ Lawrence Livermore National Laboratory
}

\section{Introduction}

Preliminary results are presented from the long-term corrosion test program of candidate materials for the high-level radioactive waste packages that would be emplaced in the potential repository at $Y$ ucca Mountain, Nevada. The present waste package design is based on a multi-barrier concept having an inner container of a corrosion resistant material and an outer container of a corrosion allowance material. Test specimens have been exposed to simulated bounding environments that may credibly develop in the vicinity of the waste packages. Corrosion rates have been calculated for weight loss and crevice specimens, and U-bend specimens have been examined for evidence of stress corrosion cracking (SCC). Galvanic testing has been started recently and initial results are forthcoming. Pitting characterization of test specimens will be conducted in the coming year. This test program is expected to continue for a minimum of five years so that long-term corrosion data can be determined to support corrosion model development, performance assessment, and waste package design.

\section{Materials}

Three classes of materials are being tested. Corrosion resistant, intermediate corrosion resistant, and corrosion allowance materials are being tested in order to determine the corrosion properties of a variety of materials.

\section{$\underline{A L L O Y}$}

Corrosion Resistant:

Alloy 825

Alloy $\mathrm{G} 3$

Alloy $\mathrm{C} 22$

Alloy $\mathrm{C} 4$

Titanium Gr 12

Titanium Gr 16

Inconel 625

Inconel 686

Corrosion Allowance:

A516 Gr 55

$\mathrm{K} 01800$

Cast Steel

J02501

2-1/4 Cr-1Mo Steel

Intermediate resistant:

Monel 400

CDA 715

\section{UNS NUMBER NOMINAL COMPOSITION}

$\begin{array}{ll}\text { N08825 } & \text { 42Ni-21Cr-3Mo-Fe(bal) } \\ \text { N06985 } & 22 \mathrm{Cr}-19 \mathrm{Fe}-7 \mathrm{Mo}-\mathrm{Ni}(\mathrm{bal}) \\ \text { N06022 } & 21 \mathrm{Cr}-13 \mathrm{Mo}-4 \mathrm{Fe}-3 \mathrm{~W}-2 \mathrm{Co}-\mathrm{Ni}(\mathrm{bal}) \\ \text { N06455 } & 16 \mathrm{Cr}-16 \mathrm{Mo}-3 \mathrm{Fe}-2 \mathrm{Co}-\mathrm{Ni}(\mathrm{bal}) \\ \text { R53400 } & 0.7 \mathrm{Ni}-.3 \mathrm{Mo}-\mathrm{Ti}(\mathrm{bal}) \\ \text { none to date } & 0.05 \mathrm{Pd}-\mathrm{Ti}(\mathrm{bal}) \\ \text { N06625 } & 22 \mathrm{Cr}-5 \mathrm{Fe}-9 \mathrm{Mo}-\mathrm{Ni}(\mathrm{bal}) \\ \text { N06686 } & 22 \mathrm{Cr}-5 \mathrm{Fe}-16 \mathrm{Mo}-\mathrm{Ni}(\mathrm{bal}) \\ & \\ & \\ \text { K01800 } & 0.2 \mathrm{C}-0.5 \mathrm{Mn}-\mathrm{Fe}(\mathrm{bal}) \\ \text { J02501 } & 0.2 \mathrm{C}-1.2 \mathrm{Mn}-\mathrm{Fe}(\mathrm{bal}) \\ \text { K21590 } & 0.15 \mathrm{C}-0.4 \mathrm{Mn}-2.25 \mathrm{Cr}-1 \mathrm{Mo}-\mathrm{Fe}(\mathrm{bal})\end{array}$

N04400 30Cu-70Ni

CDA $715 \quad 70 \mathrm{Cu}-30 \mathrm{Ni}$ 
Materials were tested in two metallurgical conditions. In addition to the unwelded condition. specimens were tested in the welded condition using gas metal arc welding (GMAW) and gas tungsten arc welding (GTAW) practices.

\section{Test Environment}

The test environments include four aqueous solutions that may simulate a range of environments to which the container materials may be exposed. The environments are briefly described as follows:

1) Simulated Dilute Well (SDW) J-13 water at $10 \mathrm{X}$ concentration: Well J13 water is thought to be typical of the vadose water in the repository ${ }^{\prime}$ and the slight concentration is intended to represent the effects of water evaporation and boiling in the repository environment, thus concentrating the salts in the water.

2) Simulated Concentrated Well (SCW) $\mathrm{J13}$ water at 1000X: The extreme concentration of water is intended to represent the long-term concentration effects brought on by evaporation and boiling of water in the repository.

3) Simulated Acidified Well (SAW) J13 water concentrated and acidified to $\mathrm{pH} \mathrm{2-3:} \mathrm{This} \mathrm{environment} \mathrm{is}$ intended to simulate the effect of possible microbial metabolic products which tend to lower the $\mathrm{pH}$ of water. Water $\mathrm{pH}$ was lowered using reagent grade acids.

4) Simulated Cement Modified Water (SCMW): This environment is intended to simulate the effect of water contact with cementitious materials which may be used in the repository construction.

The nominal compositions of the four test solutions are shown in Figure 1.

Specimens have been tested in the aqueous phase, the saturated water vapor phase above the solutions, and at the water/vapor interface. It is important to note that the specimens tested in the vapor phase had condensed water present on the surface. Testing has been conducted at 60 and $90{ }^{\circ} \mathrm{C}$ to represent a range of temperatures where liquid or condensing water may come into contact with the waste package.

\section{Test Specimens}

Four types of specimens were tested to evaluate the susceptibility of test materials to general corrosion, localized corrosion (e.g., pitting and crevice attack), galvanic/crevice corrosion, and stress corrosion cracking. A sufficient number of specimens were tested in order to remove and analyze a complete specimen set at five time intervals.

Flat 1 -inch by 2 -inch coupons were used for general and pitting corrosion studies. Weight loss data obtained from these coupons were used to calculate corrosion rates, which will provide kinetic and mechanistic information on the degradation process. Corrosion rates were calculated using methods described in ASTM G1. 2

Crevice corrosion specimens were made of flat coupons 2 -inch by 2 -inch placed in intimate contact with a Teflon washer to produce an aggressive crevice. Intimate contact between specimen and washer was maintained by using a Belleville compression washer assembly. The Belleville washers served to maintain pressure on the Teflon part in the event creep occurs, thus maintaining a configuration expected to produce severe crevice conditions. ${ }^{3}$ As with the weight loss specimens, corrosion rates were determined using methods described in ASTM GI.

The galvanic/crevice specimen assembly is intended to simulate a multi-barrier waste package concept where the highly corrosion resistant material represents the inner barrier and the corrosion allowance material represents the outer barrier. These assemblies consisted of a corrosion resistant material placed in between two corrosion allowance materials, thus forming two crevice regions, one above and the other below the corrosion resistant material. Two types of assemblies with different surface area ratios were used. As with the crevice specimen, the use of Belleville compression washers provided intimate contact between the test surfaces. 
U-bend specimens were tested to study the susceptibility of the test materials to SCC. The stresses produced on a typical U-bend specimen may result in a large amount of non-uniform elastic and plastic strain, and may provide severe test conditions to evaluate the SCC resistance of the following: 1) different metals in the same environment, 2) a single metal with different metallurgical conditions in the same environment, and 3) a single metal in several environments. ${ }^{4}$

\section{Results and Discussion}

\section{Weight Loss Specimens}

Corrosion rates for the as-fabricated corrosion allowance materials after six months exposure to SDW and SCW environments are shown in Figure 1. Corrosion rates are the average of three specimens in the liquid and vapor phase, and a single specimen at the water line. Results for the welded weight loss specimens are not presented in Figure 1, but are similar to and follow the same trends as the as-fabricated specimens. The data indicates an increased corrosion rate of the vapor phase specimens located above the SCW environment versus the vapor phase specimens located above the SDW environment. It is possible that elevated $\mathrm{CO}_{2}$ levels are being generated from the very high bicarbonate $\mathrm{SCW}$ solution which could lower the $\mathrm{pH}$ of the condensate in the vapor phase, and thus providing a more aggressive medium in this environment. This hypothesis is being investigated.

Another interesting observation is the difference in corrosion rates between specimens in the aqueous phase of the SDW and SCW solutions. All of the corrosion allowance specimens in the SCW solution had lower corrosion rates than replicate specimens in the SDW environment. It is probable that the SCW solution may have lower dissolved oxygen content. Others have observed that the solubility of oxygen decreases as the concentrations of salt solutions increase. ${ }^{5}$ The diminished availability of oxygen slows the reduction reaction rate, and hence slows the oxidation rate of iron. Dissolved oxygen measurements will be obtained in the near future to further investigate this hypothesis. It is also possible the SCW solution is inhibiting, although the inhibition mechanism for this particular solution is not currently understood. Others have shown that nitrate and fluoride, while oxidizing at lower concentrations, can passivate mild steel at higher concentrations. ${ }^{6}$ The nitrate concentration of the SDW and SCW solutions are 65 and 7,000 ppm, respectively, while the fluoride concentrations are 15 and $1,400 \mathrm{ppm}$, respectively. Testing to confirm this hypothesis will be conducted in the near future.

Corrosion rates for the corrosion resistant materials after six months exposure to $60^{\circ} \mathrm{C} \mathrm{SAW}$ were negligible. Titanium grade 12 and titanium grade 16 , however, were discolored due to oxidation.

Corrosion rates for the intermediate corrosion resistant materials after six months exposure to $60^{\circ} \mathrm{C} \mathrm{SAW}$ are shown in Figure 2, exhibiting an enhanced corrosion rate of the specimens in the aqueous phase $(\sim 100$ 300 microns per year) versus the specimens in the vapor phase. The dissolution of copper-nickel alloys might have changed the $\mathrm{pH}$ of the test solutions from a starting point of $\mathrm{pH} 2.8$ to an equilibrium value of $\mathrm{pH} 5$. The specimens exposed to the vapor phase were relatively resistant to general corrosion in this environment, with corrosion rates varying from 1-4 microns per year. The corrosion rates for CDA 715 and Monel 400 in the aqueous phase were 250 and 120 microns per year, respectively.

Quantitative pitting corrosion analysis of the weight loss specimens to determine resistance to localized corrosion will be performed on all the material classes in the near future and will be presented later.

\section{Crevice Corrosion Specimens}

Corrosion rates for the crevice corrosion specimens were determined to be similar to those of the weight loss specimens for all three materials classes, both in magnitude and trends.

Quantitative pitting corrosion analysis of the crevice specimens will be performed on all the material classes in the near future and will be presented later. Visual examination of crevice specimens showed severe pitting attack in the crevice region on Alloy 825 exposed to $60^{\circ} \mathrm{C}$ SAW solution. 


\section{U-bend Specimens}

U-bend specimens of corrosion allowance materials tested in 60 and $90{ }^{\circ} \mathrm{C} \mathrm{SDW}$ and SCW environments exhibited no evidence of SCC under light microscopy examination. Similarly, intermediate corrosion resistant materials and corrosion resistant materials exposed to $60^{\circ} \mathrm{C} \mathrm{SAW}$ exhibited no evidence of SCC under light microscopy examination.

\section{Galvanic Specimens}

Galvanic corrosion testing was initiated in September 1997. The results from these tests will be reported later.

\section{Future Work}

Characterization of the SDW and SCW solutions will be performed to understand the reason for the differences in corrosion rates in both the vapor and aqueous phase for the corrosion allowance materials tested in these environments. Testing will also include oxygen and carbon dioxide analysis, and inhibition studies.

Samples exposed for one year will be analyzed, and with the complementary six month data trending tendencies will be generated.

Pitting analysis will be performed on the samples tested to date as well as the samples removed after one year exposure. Maximum pit depth, statistical pit distribution, and in-depth pitting characterization of selected pits to determine shape, volume, and other characteristics will be performed in the near future.

The corrosion products will be characterized both compositionally and structurally. The type of corrosion products formed may have implications for radionuclide migration.

\section{Acknowledgements}

The authors wish to acknowledge the contributions of Edward Dalder, Stanley Edson, Richard Green, and Susan Poor for their efforts in the corrosion test facility construction, design, and test control.

This work was performed under the auspices of the U.S. Department of Energy by Lawrence Livermore National Laboratory under Contract W-7405-ENG-48. This work is supported by Yucca Mountain Site Characterization Project, LLNL.

\section{References}

1. J.E. Harrar, J.F.Carley, W.F. Isherwood, and E. Raber, "Report of the Committee to review the Use of J-13 Well Water in Nevada Nuclear Waste Storage Investigations," Lawrence Livermore National Laboratory report UCID-21867, Livermore California, January 1990.

2. Standard G1-81, "Standard Practice for Preparing, Cleaning, and Evaluating Corrosion Test Specimens," Annual Book of ASTM Standards, Vol. 3.02, American Society for Testing and Materials, Philadelphia, PA, 1987.

3. J.W. Oldfield, W.H. Sutton, "Crevice Corrosion of Stainless Steels," Br. Corrosion J., 13(1978)13.

4. Standard G30-79 (Reapproved 1984), "Standard Practice for Making and Using U-bend Stress Corrosion Test Specimens," Annual Book of ASTM Standards, Vol. 3.02, American Society for Testing and Materials, Philadelphia, PA, 1987.

5. S.D. Cramer, "The Solubility of Oxygen in Geothermal Brines," Corrosion Problems In Energy Conversion And Generation, The Electrochemical Society, Incorporated, 1974, pp 251-262. 
6. Dora M. Brasher,"Stability of the Oxide Film on Metals in Relation to Inhibition of Corrosion II. Dual Role Of The Anion In The Inhibition Of The Corrosion Of Mild Steel," Br. Corrosion J., $4(1969) 122$. 
Figure 1.

Corrosion Allowance Materials in 60 and $90^{\circ} \mathrm{C}$ SDW and SCW Environments

As-Fabricated Alloy Steel in $60 \mathrm{C}$ Environment

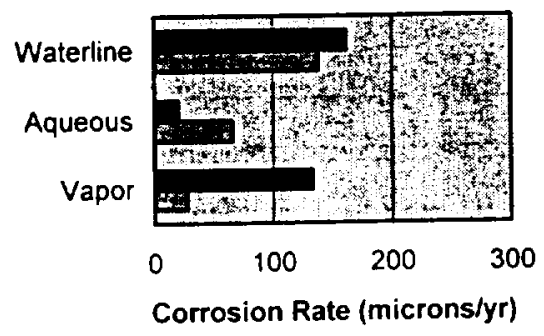

SCW

SDW
As-Fabricated Alloy Steel in $90 \mathrm{C}$ Environment

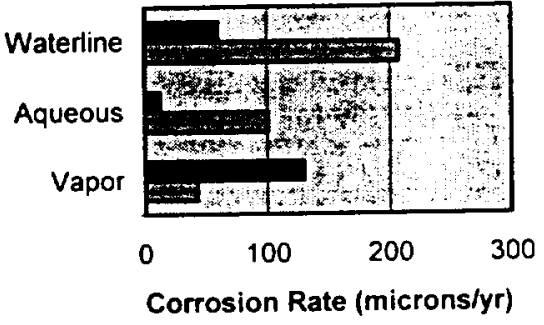

asCW

ESDW
As-Fabricated Carbon Steel in $60 \mathrm{C}$ Environment

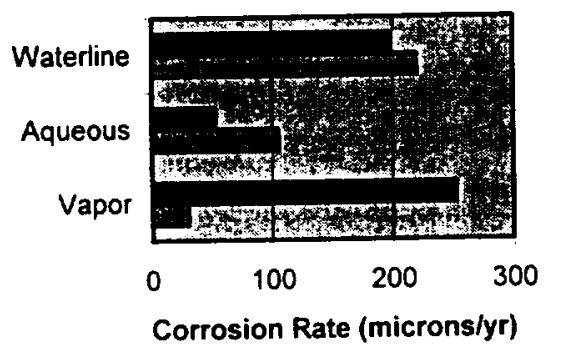

As-Fabricated Cast Steel in $60 \mathrm{C}$ Environment

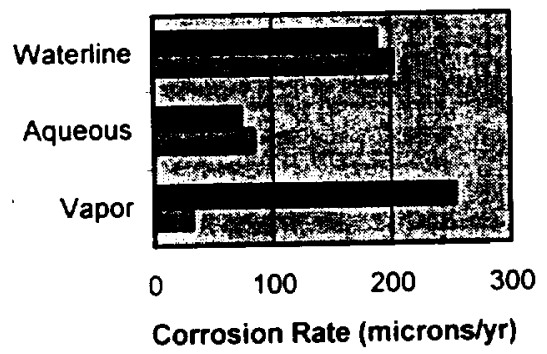

As-Fabricated Carbon Steel in $90 \mathrm{C}$ Environment

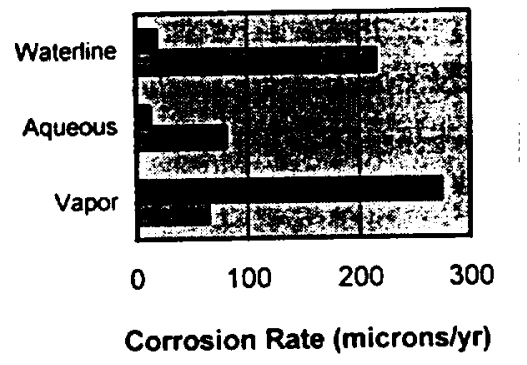

As-Fabricated Cast Steel in $90 \mathrm{C}$ Environment

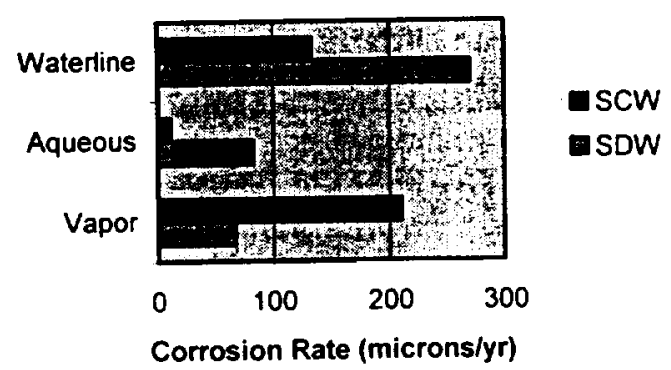


Figure 2.

Intermediate Corrosion Resistant Materials in $60^{\circ} \mathrm{C} \mathrm{SAW} \mathrm{Environment}$
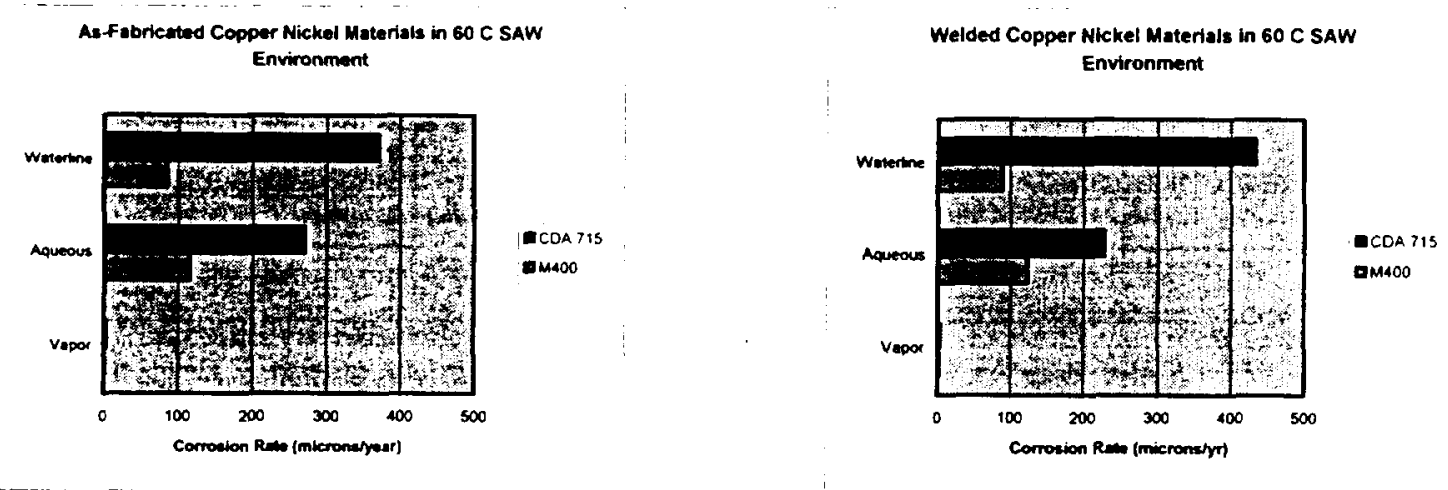

Table 1.

Nominal Composition of Test Solutions (ppm)

\begin{tabular}{|c|c|c|c|c|c|c|c|c|c|c|}
\hline Solution & $\underline{\mathrm{Ca}}$ & $\underline{\mathrm{Mg}}$ & $\underline{K}$ & $\underline{S i}$ & $\underline{\mathrm{Na}}$ & Sulfate & Chloride & Nitrate & Fluoride & Bicarbonate \\
\hline SDW & 4 & 1 & 83 & 3.5 & 400 & 170 & 67 & 63 & 13 & 650 \\
\hline SCW & 15 & 3 & 4,500 & 58 & 44,000 & 13,000 & 7,500 & 7,200 & 1400 & 51000 \\
\hline SAW & 60 & 53 & 4300 & 32 & 43000 & 40000 & 25000 & 23000 & 0 & 0 \\
\hline SCMW & 453 & 4 & 87 & 13 & 11 & 1220 & 28 & 10 & $<1$ & 9 \\
\hline
\end{tabular}


Technical Information Department • Lawrence Livermore National Laboratory

University of California • Livermore, California 94551

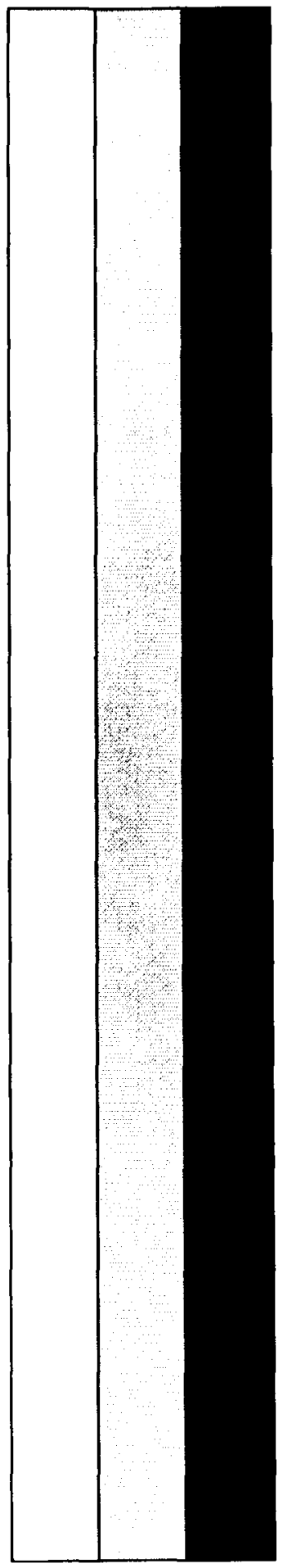

